\title{
Validação do processamento térmico de um produto protéico vegetal enlatado
}

\author{
Gladistone Carvalho Santos Filho, Thereza Christina Vessoni Penna*
}

Departamento de Tecnologia Bioquímico-Farmacêutica, Faculdade de Ciências Farmacêuticas, Universidade de São Paulo

*Correspondência:

T. C. V. Penna

Departamento de Tecnologia

Bioquímico-Farmacêutica

FCF/USP

Cx Postal 66083, CEP 05315-970

E-mail: tcrpenna@usp.br
A validação de processos nas indústrias alimentícia e farmacêutica é uma das principais ferramentas da garantia de qualidade, tornando os produtos seguros, eficazes e confiáveis.Realizou-se a validação física e biológica da esterilização terminal de um produto protéico constituído de proteína texturizada de soja, proteína de trigo (glúten), gordura vegetal hidrogenada e condimentos, envasado em latas metálicas de 850 gramas. A validação física do autoclave foi executada em três ciclos na câmara com 12 sensores de temperatura. Confirmou-se para os pontos geometricamente distribuídos no interior do autoclave que a diferença máxima de temperatura entre um ponto e outro foi de $1,0^{\circ} \mathrm{C}$ em relação à temperatura média da câmara $\left(121^{\circ} \mathrm{C}\right)$. Nos ciclos realizados com carga máxima, o menor valor $F_{121^{\circ} \mathrm{C}}^{10^{\circ} \mathrm{C}}(64,86$ minutos) garantiu S.A.L.(Sterility Assurance Level ou nivel de garantia de esterilidade) de pelo menos $10^{-12}$ em relação ao indicador biológico de Bacillus stearothermophilus ATCC 7953 (valor $D_{121^{\circ} \mathrm{C}}$ de 3,68 minutos e população média de 1,00 × $10^{6}$ esporos por fita). Para todas as operações de esterilização a presença de esporos sobreviventes no indicador biológico não foi detectada.Apesar de não existir margem de segurança definida para esterilização de alimentos enlatados, a validação periódica de um autoclave proporcionou maior confiabilidade na avaliação da esterilidade, que o simples teste de incubação por amostragem de produtos acabados, recomendado pelo Ministério da Saúde do Brasil.
Unitermos

- Validação

- Bacillus stearothermophilus

- Autoclave

- Esterilização

- Alimentos enlatados

\section{INTRODUÇÃO}

Validar é estabelecer critérios documentados para assegurar a execução de procedimentos de maneira reprodutível (PDA, 2000).
Para que a validação seja colocada efetivamente em prática, deve ser conduzida de forma organizada. A validação pode ser dividida nas seguintes etapas: Qualificação de Instalação, Qualificação Operacional e Qualificação de Processo. 
Num processo de esterilização, a Qualificação de Instalação envolve a qualificação dos equipamentos e instrumentos que tornam o esterilizador operacionável. Um programa de qualificação do autoclave deve ser estabelecido para demonstrar que o equipamento é capaz de ser operado rotineiramente, nos padrões especificados.

A Qualificação Operacional refere-se à verificação se o equipamento é operável conforme as especificações. Estabelece a condição de operação regular, como: distribuição de calor na câmara vazia, pressão na câmara interna e na jaqueta. Executa-se investigação dos controles das variáveis do processo, incluindo procedimentos operacionais escritos e treinamento de pessoal. O objetivo é avaliar se o equipamento e sistema estão prontos para operar o produto.

Na Qualificação de Performance ou Validação de Processo, realizada após as qualificações da instalação e operação, o equipamento ou sistema é testado com o produto para determinar se o processo é efetivo e reprodutível, atendendo as especificações e os requisitos de qualidade.

Cada etapa de qualificação, antes de ser executada, deve ser protocolada e validada. Segundo definição do FDA (Guideline on General Principles of Process Validation 1987), o Protocolo de Validação é um plano escrito, estabelecendo como a validação deve ser conduzida (Vessoni Penna,1997).

A norma internacional mais utilizada para validação de processos de esterilização é a ISO11.134:1995 "Sterilization of Health Care Products-Requirements for validation and routine control - Industrial moist heat sterilization" (ISO,1994). No Brasil, não possuímos uma norma específica para validação de processos da indústria alimentícia, apenas a Portaria de $\mathrm{n}^{0} .500$ de 13/10/1997, Anexo I, do Ministério da Saúde, que trata da "Validação Do Processo de Esterilização por Vapor" para produtos parenterais esterilizados termicamente (Brasil,1997).

Para avaliar o efeito do tratamento térmico em termos de número de ciclos reduzidos na população microbiana inicial, o valor $\mathrm{F}_{\mathrm{Tr}}$ deve ser determinado. Valor $\mathrm{F}_{\mathrm{Tr}}$ é o intervalo de tempo de aquecimento necessário, à temperatura de referência constante, para se obter o nível de destruição pré-estabelecido (n). Para calcular o valor $\mathrm{F}_{\mathrm{Tr}}$ é necessário conhecer a variação da temperatura do produto com o tempo de processo (Vessoni Penna, 1997).

No processamento de alimentos enlatados de baixa acidez, a esterilização terminal é a etapa do processo que garante o nível de esterilidade do produto final. O nível de esterilidade é definido como o número de microrganismos viáveis, que sobrevivem à esterilização por unidade do produto considerado. A definição dos parâmetros operacionais do método de esterilização escolhido determina a margem de segurança do produto ou a probabilidade de falha do sistema (Ishisaki,1998).

Os produtos protéicos vegetais, também chamados de análogos de carne, são produtos processados a partir de proteínas vegetais similares à carne em textura e sabor. São produtos alimentícios constituídos de proteína texturizada de soja, proteína de trigo (glúten), gordura vegetal hidrogenada e condimentos, de aparência similar a uma carne moída. No Brasil, são produtos prontos para o consumo, disponíveis em supermercados e utilizados em inúmeras receitas da culinária vegetariana, sendo também comercializados como suplemento nutricional, especialmente para crianças e adultos em programas públicos institucionais. O produto tem a seguinte composição centesimal: proteínas $(19,98 \%)$, gorduras $(1,63 \%)$, carboidratos $(3,05 \%)$, fibras $(1,29 \%)$, ferro $(0,2 \%)$, fósforo $(0,6 \%)$ e teor de umidade $(69,98 \%)$

Face ao exposto, os objetivos do trabalho foram: (i) avaliação operacional do autoclave industrial, tipo estática por lotes, com injeção de vapor saturado, à temperatura de referência de $121{ }^{\circ} \mathrm{C}$. (ii) validação do desempenho do autoclave utilizando-se de termopares para validação física e de esporos de Bacillus stearothermophilus ATCC 7953 para validação biológica.

\section{MATERIAL E MÉTODOS}

\section{Material}

\section{Características gerais do autoclave}

Autoclave cilíndrico (2,5 m x 1,2 m; Quiminox, SP, Br) com capacidade de 2.800 litros, construída de chapas de aço carbono 1020 (espessura $1 / 4$ de polegada), com uma porta provida de aberturas e travas circulares, junta vedante de anel de amianto alojada em uma canaleta entre a câmara e a porta. Conforme a Figura 1, a autoclave possui os seguintes acessórios de controle: (a) um termômetro de mercúrio (0 a $150{ }^{\circ} \mathrm{C}$; Salcas, $\left.\mathrm{SP}, \mathrm{Br}\right)$; (b) um manômetro galvanométrico ( 0 a $5 \mathrm{kgf} / \mathrm{cm}^{2}$; Wika, $\mathrm{SP}, \mathrm{Br}$ ); (c) 3 válvulas solenóides (Valcon, SP, Br) para entrada de vapor (c1 e c2) e de ar comprimido(c3); (d) uma válvula de segurança (Spirax Sarco, SP, Br) calibrada à pressão de operação de $2,0 \mathrm{kgf} / \mathrm{cm}^{2}$; (e) um registro tipo gaveta (1 1 1/2 pol; Valflux, SP, Br) para entrada de água de resfriamento; (f) duas válvulas ( $1 \frac{1}{2}$ pol Spirax Sarco, SP, Br) eliminadoras de ar; (g) um controlador de temperatura Proporcional Integral Derivativo - PID - (Spirax Sarco, SP, Br) com auto ajuste, que controla as válvulas de entrada de vapor; (h) um sensor de temperatura tipo PT100 (Salcas, $\mathrm{SP}, \mathrm{Br}$ ) com poço termométrico conectado ao controlador 
PID; (i) um registro tipo gaveta (2 1/2 pol Valflux, SP, Br) para drenagem da água da autoclave.

O sistema de aquecimento é realizado através de vapor saturado à pressão de $2,0 \mathrm{kgf} / \mathrm{cm}^{2}$, sendo o vapor gerado por uma caldeira (6000 kgvapor/h; ATA, SP, Br) e distribuído na câmara através de uma tubulação (1 pol) provido de aberturas oblongas ( $1 / 4 \mathrm{pol})$, que se estendem ao longo do fundo do equipamento. Ao final do ciclo de aquecimento mistura de vapor(c2) e ar comprimido (c3)é injetada para compensação de pressão nas latas.

Sistema de contra-pressão é realizado através da injeção direta de ar comprimido (c3) seco e isento de óleo.

Para o resfriamento das latas, água potável com teor residual de $5 \mathrm{ppm}$ de cloro livre (hipoclorito de sódio), é recirculada na câmara com vazão de $15 \mathrm{~m}^{3} / \mathrm{h}$, na forma de cortina de água. A água é pressurizada através de tubulação ( $3 / 4 \mathrm{pol})$, provida de bicos tipo "spray", que se estende ao longo da parte superior da câmara, de forma a manter fluxo vertical homogêneo. (j). A água drenada (i) é bombeada para uma torre de resfriamento, retornando ao tanque pulmão de abastecimento.

\section{Equipamentos utilizados na validação}

O equipamento utilizado para aquisição dos dados de temperatura e pressão foi um sistema validador da "Kaye Instruments" série 306298 (Bedford, USA), provido de coletor de dados de temperatura e pressão, conectado a um computador PC Pentium 233. Doze cabos de 10 metros, compensados (bitola $32 \mathrm{AWG),} \mathrm{revestidos}$ em teflon/teflon foram utilizados como extensão do coletor de dados. Os sensores de temperatura foram termopares tipo $\mathrm{T}$ [combinação de metais cobre $(+) /$ cobreníquel(-)], montados em bainha de aço inoxidável (3,2 x $100 \mathrm{~mm}$ ), ajustáveis em conector compensado tipo macho-fêmea. Antes e depois de cada ciclo, os termopares foram calibrados em forno (Hart Scientifc - modelo $9100 \mathrm{~B}$, série 66728 ), na faixa de temperatura entre $50{ }^{\circ} \mathrm{C}$ e $400{ }^{\circ} \mathrm{C}$, apresentando variação de temperatura de \pm

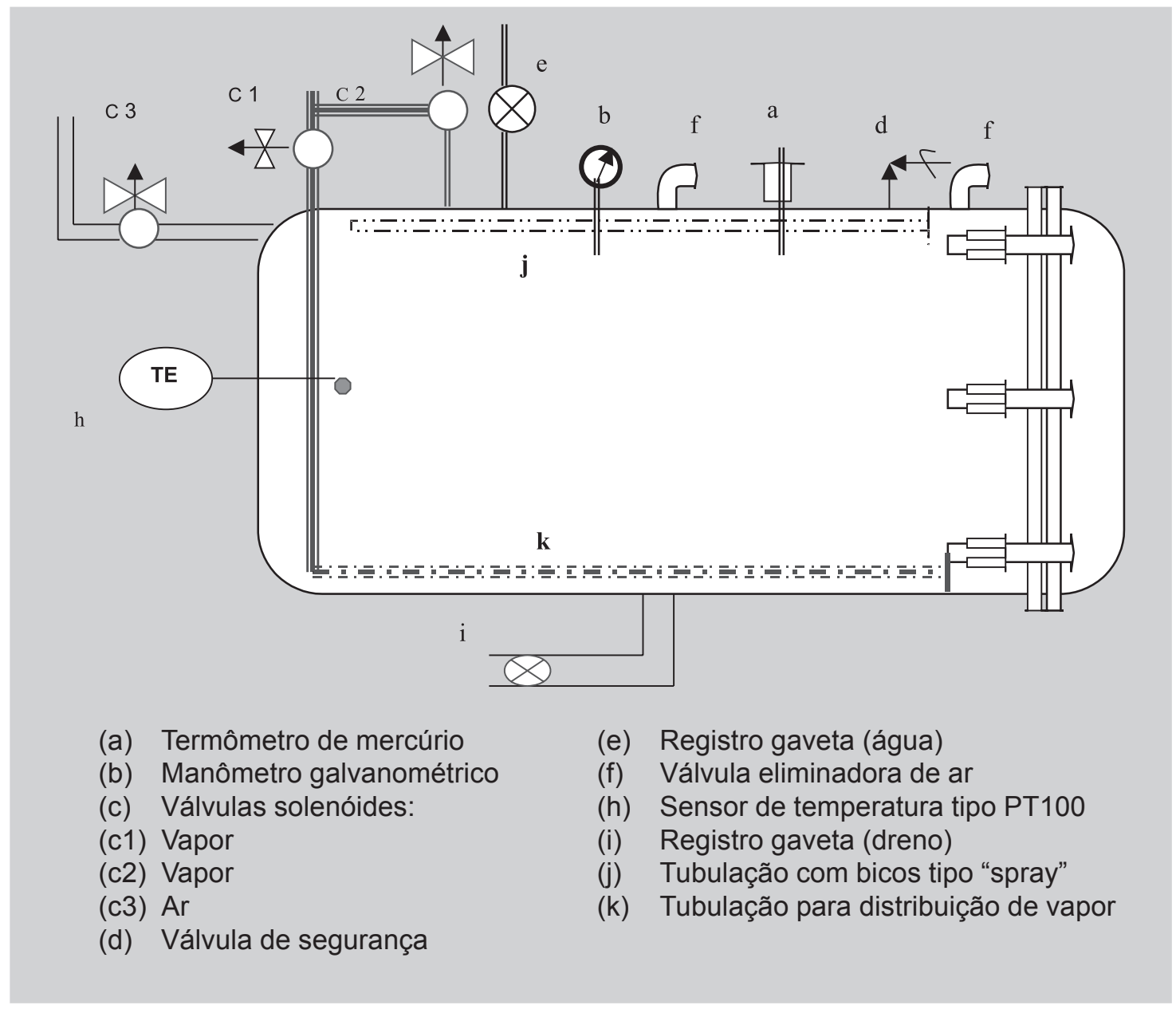

FIGURA 1 - Autoclave horizontal. 
$0,2{ }^{\circ} \mathrm{C}$ em relação ao termômetro de referência (PT 100, Kaye Instruments, $\left.n^{\circ} 1269\right)$.

\section{Produto}

Oitocentos e cinqüenta gramas do produto protéico vegetal à base de soja e glúten (massa úmida, cominuída, granulada, de coloração marrom-clara, $\mathrm{pH} 6,3 \pm 0,2)$ foram envasados em lata metálica cilíndrica $(99 \times 118 \mathrm{~mm})$, com revestimento interno de verniz sanitário epoxifenólico e tampa para recravação. Para a formulação do produto foram utilizados: glúten de trigo em pó, proteína texturizada de soja, gordura vegetal hidrogenada, glutamato monossódico, alho e cebola desidratados, sal, flavorizante sabor carne e corante caramelo. A Figura 2 apresenta um fluxograma geral do processo de fabricação do produto protéico vegetal.

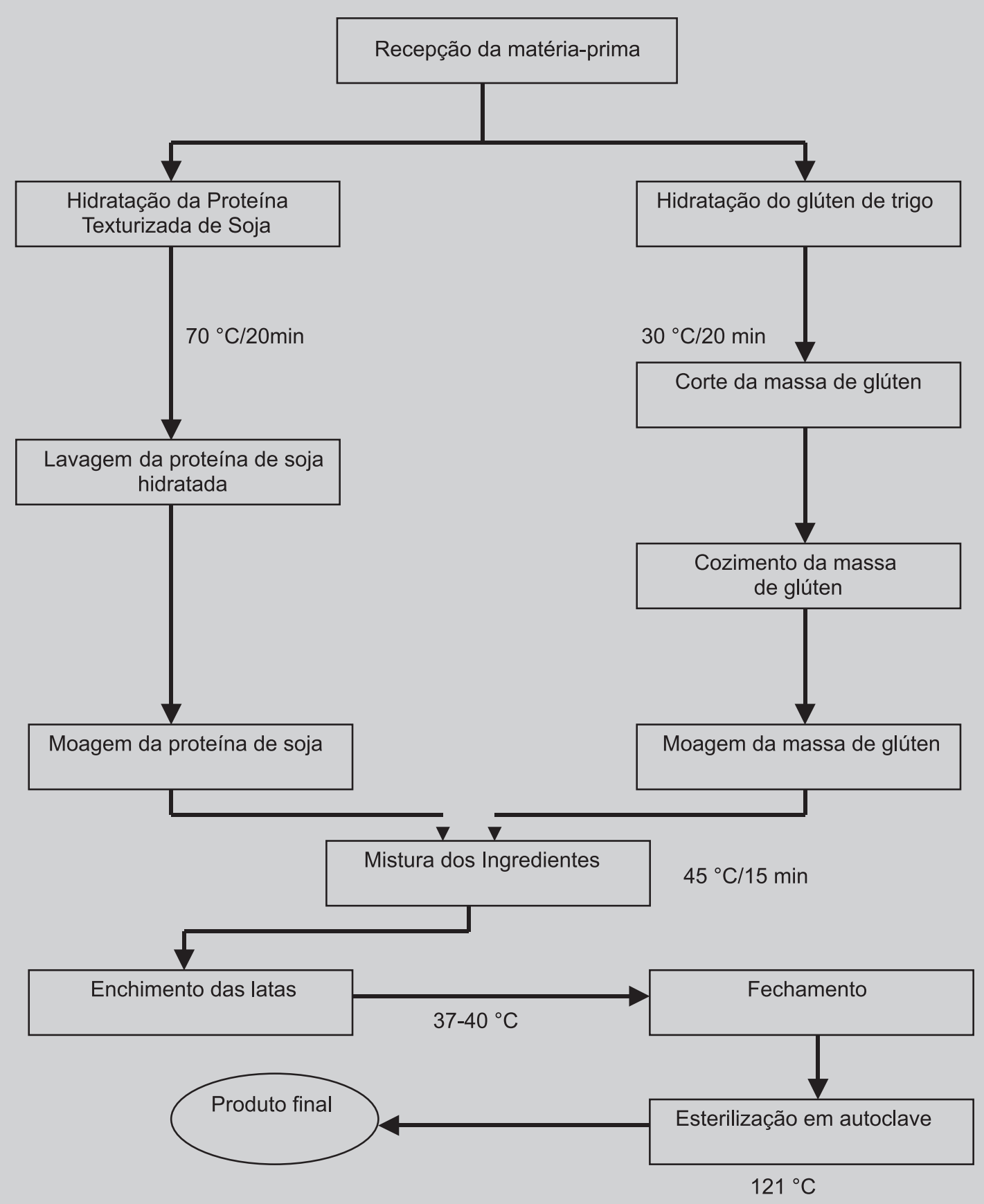

FIGURA 2 - Fluxograma geral do processo. 


\section{Carga de esterilização}

A unidade de carga foi representada por lata metálica cilíndrica $(99$ x $118 \mathrm{~mm})$, com revestimento interno de verniz sanitário epoxifenólico e tampa para recravação, contendo $850 \mathrm{~g}$ do produto, perfazendo $950 \mathrm{~g}$ de massa total. Em cada carrinho de aço inoxidável $(80 \times 80 \times 80$ $\mathrm{cm}$ ), foram acomodadas 366 latas. Na câmara do autoclave foram dispostos três carrinhos, caracterizando a carga máxima de $950 \mathrm{~kg}$ de produto final.

\section{Métodos}

\section{Estudo de Distribuição de Calor na Câmara}

A Qualificação Operacional (QO) teve por objetivos: (1) verificar a calibração do autoclave, acessórios periféricos e operacionais; (2) confirmar a operacionalidade do equipamento executando 3 ciclos na câmara do autoclave, adequando a distribuição de calor aos pares tempo-temperatura estabelecidos. Doze sensores de temperatura foram distribuídos no espaço geométrico da câmara (figura 3) sem tocarem a superfície da mesma durante os estudos de distribuição e penetração de calor. Um dos sensores permaneceu justaposto ao sensor de comando do autoclave, que foi ajustado à temperatura de $121^{\circ} \mathrm{C}$ durante 20 minutos.

\section{Estudo da Penetração de Calor na Unidade de Carga}

Para a Qualificação de Performance (QP) onze termopares foram introduzidos nos produtos e posicionados no centro geométrico das latas. As unidades de carga com sensores foram distribuídos na câmara nas mesmas posições pré-estabelecidas (Figura 3).

Para a carga máxima do produto no autoclave, o sensor de comando da mesma foi ajustado em $125^{\circ} \mathrm{C}$ para os 90 minutos iniciais do ciclo e em $121{ }^{\circ} \mathrm{C}$ para os 30 minutos seguintes. As temperaturas dos sensores foram registradas automaticamente a intervalos de 60 segundos.

\section{Validação Biológica}

Determinação do valor D no produto protéico vegetal

Foram utilizados como indicadores biológicos esporos de B. stearothermophilus ATCC 7953 desenvolvidos a $65^{\circ} \mathrm{C}$ por 6 dias em PCA (plate count agar) suplementado com amido solúvel, $0,10 \%$; sulfato de magnésio, $0,05 \%$; sulfato de manganês, $0,05 \%$; cloreto de cálcio, $0,05 \%$; ao valor final de $\mathrm{pH} 7,0 . \mathrm{O}$ crescimento foi suspenso em solução de acetato de cálcio $0,02 \mathrm{M}$, ao valor de $\mathrm{pH}$ 9,7 ajustado com solução de hidróxido de cálcio saturado $0,14 \%(\mathrm{p} / \mathrm{v})$, e a suspensão centrifugada por qua-

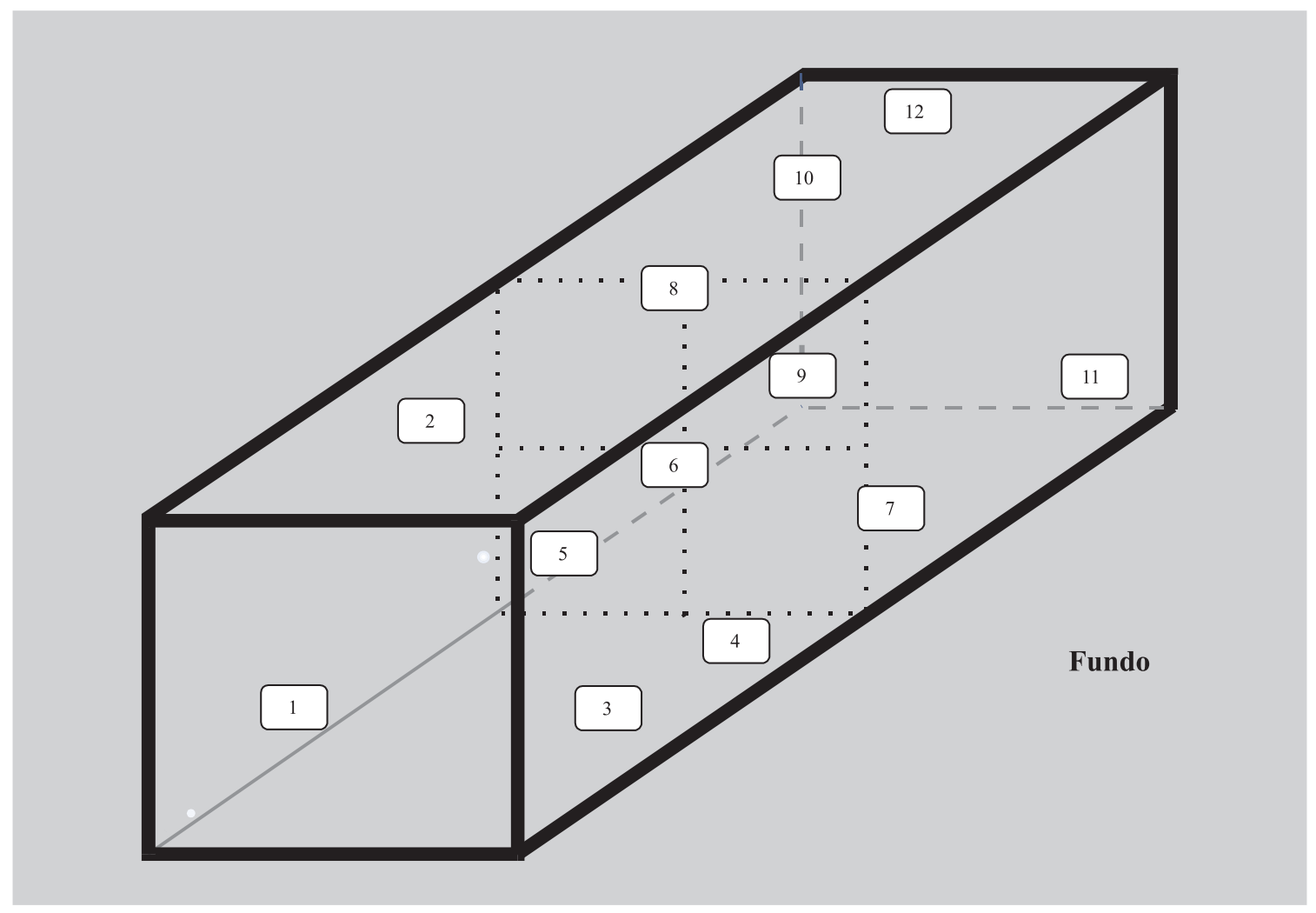

FIGURA 3 - Posição do Sensores na Câmara e com Carga Máxima. 
tro vezes a $2000 \mathrm{xg} / 30 \mathrm{~min}$. Os esporos foram suspensos em solução resfriada de acetato de cálcio $0.02 \mathrm{M}$ e a suspensão foi ajustada a pH 9,7 $\left(\mathrm{Ca}(\mathrm{OH})_{2}, 0.14 \%\right)$, sendo armazenada a $4{ }^{\circ} \mathrm{C}$ e utilizada conforme a necessidade. A contagem dos esporos viáveis de $10^{6}$ a $10^{7} \mathrm{UFC} / \mathrm{mL}$ (Unidades Formadoras de Colônias por $\mathrm{mL}$ ) após ativação térmica $\left(98,7^{\circ} \mathrm{C} / 30 \mathrm{~min}\right)$ foi estimada através de semeadura em profundidade em TSA (Trypticase Soy Agar) a $65^{\circ} \mathrm{C} /$ $48 \mathrm{~h}$.

Em condições assépticas, amostras de $15 \mathrm{~g}$ do produto transferidas para cada um dos seis frascos de vidro cilíndricos $(15 \times 50 \mathrm{~mm})$ de capacidade $15 \mathrm{~mL}$, inoculadas com 1,0 mL da suspensão de esporos, à concentração final de $1.0 \times 10^{6}$ esporos $/ \mathrm{mL} /$ frasco. Os frascos foram fechados com tampas de borracha e lacres de alumínio, sendo em seguida imersos em banho de óleo de silicone DC 200 fluid 20 cs (Haven Automation Ltd.; nº́rie 43793/12; Swansea, U.K.) termostaticamente controlado à temperatura de $(121 \pm 0,1)^{\circ} \mathrm{C}$. Para determinação do intervalo de inércia, um termopar tipo PT100 foi inserido no interior de um dos frascos, através da tampa de borracha e selado com cola de silicone. Os frascos foram retirados nos tempos de tratamento pré-determinados $(0,5,10,20 \mathrm{e}$ $30 \mathrm{~min}$ ) e resfriados em banho de água contendo gelo. A contagem dos sobreviventes foi realizada por semeadura em profundidade em TSA. As placas foram incubadas em estufa a $65^{\circ} \mathrm{C}$ durante 24 e 48 horas.

\section{Análises microbiológicas nos pontos críticos do processo de fabricação}

Para estudo da população de microrganismos viáveis nas matérias primas, e produto final antes da esterilizaçao (bioburden), foram realizadas análises nas seguintes etapas da fabricação: glúten de trigo moído, proteína de soja moída, mistura dos ingredientes, envase em latas e produto final (Figura 2). Dez amostras de lotes diferentes de produção foram analisadas, sendo que cada unidade de amostra foi composta de 03 unidades do mesmo lote, conforme procedimento estabelecido pela Resolução-RDC no 12, de 2 de Janeiro de 2001, da ANVISA (Agência Nacional de Vigilância Sanitária), Ministério da Saúde - Anexo: "Regulamento técnico sobre os padrões microbiológicos para alimentos" (Brasil, 2001).

As análises realizadas foram: contagem de bactérias mesófilas aeróbias e anaeróbias, termófilas aeróbias e anaeróbias, esporos de mesófilas aeróbias e anaeróbias, esporos de termófilas aeróbias e anaeróbias, bolores e leveduras, coliformes totais e fecais. As metodologias para amostragem, colheita, acondicionamento, transporte e análise microbiológica das amostras obedeceram ao disposto no "Compendium of Methods for the Microbio- logical Examination of Foods"(APHA,1992).

\section{Análise dos resultados}

Para a análise dos resultados foram calculados:

- Valor $\mathrm{D}_{\mathrm{Tr}}$ : estimado através do inverso negativo do coeficiente angular da equação da reta calculada, utilizando-se do método da regressão linear, através dos mínimos quadrados, aplicado à região linear da curva de sobrevivência, obtida da relação entre o logaritmo decimal da contagem de sobreviventes e o tempo de exposição respectivo. A variância do valor $\mathrm{D}$ foi calculada através da fórmula: $\mathrm{V}(\mathrm{D})=\left[1 /(-\mathrm{b})^{2}\right]^{2}[\mathrm{SE}(\mathrm{b})]^{2}$, onde b é o coeficiente angular da equação da reta, obtida por regressão linear simples, que ajusta os pares dos valores de sobreviventes e tempos de exposição a $121^{\circ} \mathrm{C}$; SE(b) é o erro padrão do coeficiente angular. $\mathrm{O}$ desvio padrão amostral em relação ao valor $\mathrm{D}$, foi obtido da raiz quadrada da variância, ou seja $S(D)=$ $\mathrm{vV}(\mathrm{D})$. O intervalo de confiança do valor D obtido foi estabelecido em $\mathrm{D} \pm \mathrm{S}(\mathrm{D})$.

- Valor $\mathrm{F}_{\mathrm{Tr}}$ : tempo equivalente $\left(\mathrm{F}_{121^{\circ} \mathrm{C}} 0^{\circ} \mathrm{C}\right)$ à temperatura de referência $\left(\mathrm{T}_{\mathrm{r}}=121^{\circ} \mathrm{C}\right)$ e $\mathrm{z}=10^{\circ} \mathrm{C}$, em relação à $\mathrm{T}_{\mathrm{M}}$ (média aritmética das temperaturas registradas para cada intervalo de tempo), foi calculado pela equação: $\mathrm{F}_{121^{\circ} \mathrm{C}}{ }^{\circ 0^{\circ} \mathrm{C}}=1 \times 10^{(\mathrm{T}-121 \mathrm{C}) / 10 \mathrm{C}}$, através da aplicação do método trapezoidal de Patashnik (Vessoni Penna, 1997).

- Valor de $\mathrm{F}_{\mathrm{Tr}}$ acumulado: refere-se ao $\mathrm{F}_{121^{\circ} \mathrm{C}}{ }^{10^{\circ} \mathrm{C}}$ obtido pela soma dos valores correspondentes ao intervalo de tempo considerado.

- Valor " $\mathrm{n}$ ": número de ciclos logarítmicos reduzidos para cada intervalo de tempo e $\mathrm{T}_{\mathrm{M}}$ considerado, calculado pela equação:

$$
n=\frac{F_{121^{\circ} \mathrm{C}}^{10^{\circ} \mathrm{C}}}{D_{121^{\circ} \mathrm{C}}}
$$

- Valor " $n$ " acumulado: refere-se à soma dos valores " $n$ " para o intervalo de tempo considerado. Ao final do ciclo representou o número de ciclos logarítmicos reduzidos do ciclo.

- Log Nf: logarítmo decimal da população final de esporos (Nf) no indicador biológico (IB), para o intervalo de tempo considerado, obtido pela equação:

$$
\log N f=\log N_{0}-\left(\frac{F_{121^{\circ} \mathrm{C}}^{10^{\circ} \mathrm{C}}}{D_{121^{\circ} \mathrm{C}}}\right) \text {, em que: }
$$

$\mathrm{N}_{0}$ : população inicial de esporos, ou seja de $1,0 \times 10^{6}$ UFC/fita. $\mathrm{O}$ valor $\mathrm{D}_{121^{\circ} \mathrm{C}}$ do IB utilizado nos ciclos foi de 3,68 $\pm 0,43$ minutos; 
Nf: população final de esporos/IB.

- S. A. L (Nível de garantia de esterilidade ou "Sterility Assurance Level”): Nf inferiores a $10^{\circ}$ esporos/IB

\section{RESULTADOS E DISCUSSÃO}

\section{Valor $\mathrm{D}_{\mathrm{T}_{\mathrm{r}}}$ de esporos de $B$. stearothermophilus no produto protéico vegetal}

A Figura 4 apresenta a curva de sobreviventes obtida a partir dos dados experimentais, representando os logaritmos de UFC/mL contra os tempos de exposição. O valor $\mathrm{D}_{121^{\circ} \mathrm{C}}$ foi calculado como o inverso negativo do coeficiente angular da equação da reta calculada utilizandose do método da regressão linear, através dos mínimos quadrados, aplicado à região linear da curva de sobrevivência, com coeficiente de correlação (r) de 0,96 . O valor $D_{121^{\circ} \mathrm{C}}=3,68 \pm 0,43 \mathrm{~min}$. obtido no produto protéico vegetal foi similar a alguns valores descritos na literatura para B. stearothermophilus (Martinez,1996). A variância do valor $\mathrm{D}_{121^{\circ} \mathrm{C}}$ foi calculada; $V(D)=0,1889402$ e o desvio padrão amostral $(S D)=0,43$.

\section{Qualificação do equipamento pelo estudo de distribuição de calor na câmara}

Após a realização da Qualificação de Instalação, que verificou se todos os equipamentos satélites e os instrumentos do autoclave, estavam dentro dos padrões especificados, passou-se para a QO, através da realização de 3 ciclos de distribuição de calor na câmara do autoclave.
Os resultados dos dados coletados são mostrados na Tabela I, referente à temperatura média, desvio padrão e valores de $\mathrm{F}_{121^{\circ} \mathrm{C}} 0^{10^{\circ} \mathrm{C}} \mathrm{em}$ minutos, para cada ponto em cada ciclo.

Para o tempo de processo de 49 minutos, o valor $\mathrm{F}_{121{ }^{\circ} \mathrm{C}} 0^{1{ }^{\circ} \mathrm{C}}$ médio foi de 46 minutos. Com o valor $\mathrm{D}_{121^{\circ} \mathrm{C}}=3,68 \pm 0,43$ minutos para os esporos de $B$. stearothermophilus e a população inicial $\left(1,0 \times 10^{6}\right.$ esporos $/ \mathrm{mL}$ ) conhecidos, se simulássemos o número de ciclos log reduzidos de esporos de IBs seria 12,57 e o nível de segurança SAL de $10^{-7}$ seria atingido.

Os estudos realizados na câmara do autoclave mostraram que em todos os pontos monitorados é atingida a temperatura desejada, a diferença de temperatura entre os pontos mais frio e mais quente foi inferior a $1{ }^{\circ} \mathrm{C}$ e, também, foi constatado que os ciclos foram repetitivos. Portanto, pode-se afirmar que os equipamentos estão operando adequadamente dentro do esperado e especificado e, conseqüentemente, qualificado para a esterilização do produto protéico vegetal a $\mathrm{T}=121^{\circ} \mathrm{C}$.

\section{Qualificação do processo pelo estudo de penetração de calor na carga máxima de produtos}

Os dados obtidos estão apresentados na Tabela II, referente ao valores de $\mathrm{F}_{121^{\circ} \mathrm{C}}{ }^{10^{\circ} \mathrm{C}}$, em minutos, em cada ponto monitorado para cada ciclo de penetração de calor. A Figura 5 apresenta os valores de $\mathrm{F}_{121^{\circ} \mathrm{C}}{ }^{1{ }^{\circ} \mathrm{C}}$ acumulado e S.A.L em relação ao tempo de processo, para cada ciclo de penetração de calor na carga máxima.

Conforme a Tabela II, o menor valor obtido de

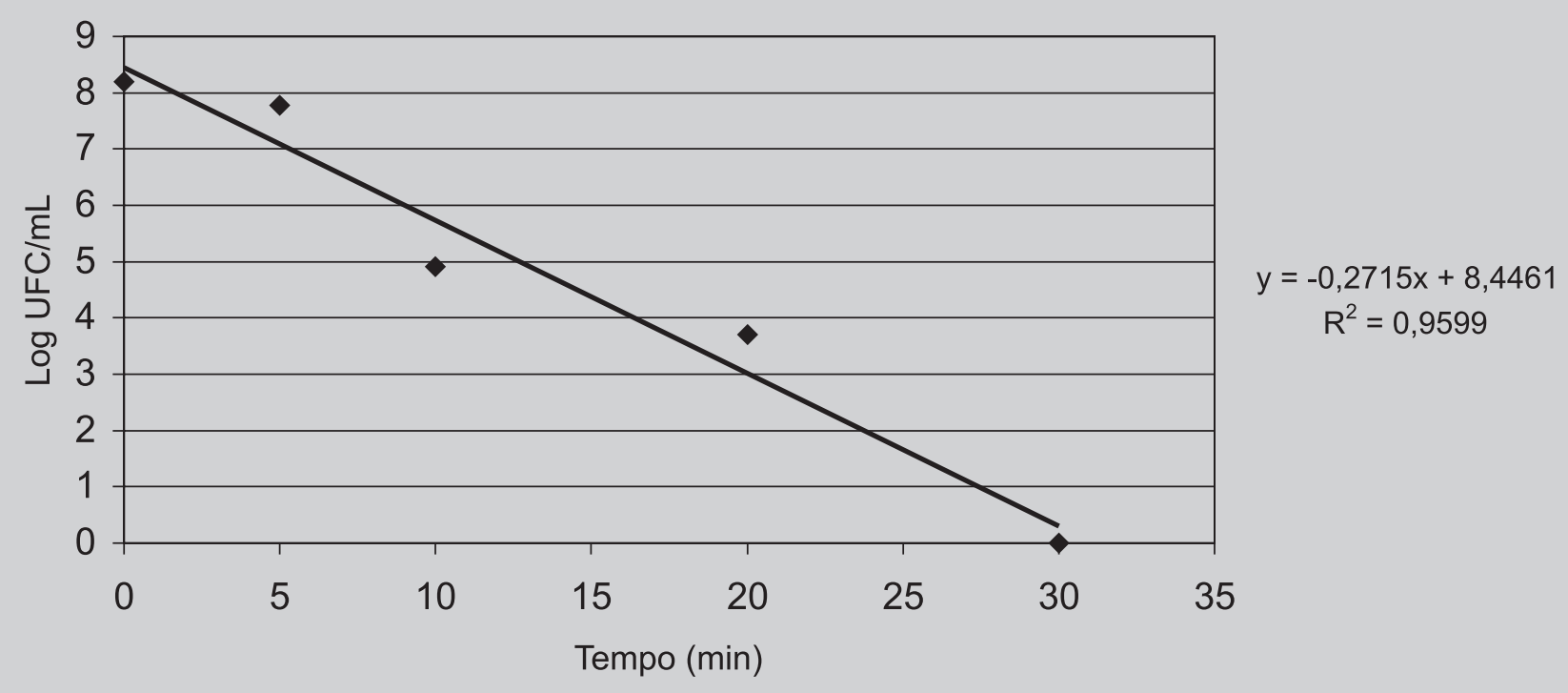

FIGURA 4 - Curva de sobreviventes. 
TABELA I - Valores de temperatura média $\left({ }^{\circ} \mathrm{C}\right)$ e de $\mathrm{F}_{121^{\circ} \mathrm{C}}{ }^{\circ{ }^{\circ} \mathrm{C}}$, em minutos, para cada ponto dentro da câmara em cada ciclo

\begin{tabular}{|c|c|c|c|c|c|c|c|c|c|c|c|c|c|}
\hline & \multicolumn{12}{|c|}{ Pontos } \\
\hline & & 01 & 02 & 03 & 04 & 05 & 06 & 07 & 08 & 09 & 10 & 11 & 12 \\
\hline \multirow[t]{3}{*}{ Ciclo 01} & $\operatorname{Temp}\left({ }^{\circ} \mathrm{C}\right)$ & $121,14 \pm$ & $121,18 \pm$ & $120,89 \pm$ & $120,96 \pm$ & $120,95 \pm$ & $121,14 \pm$ & $120,93 \pm$ & $120,98 \pm$ & $121,01 \pm$ & $120,90 \pm$ & $120,93 \pm$ & $120,99 \pm$ \\
\hline & média $\pm \mathrm{SD}$ & 0,46 & 0,48 & 0,46 & 0,44 & 0,51 & 0,51 & 0,49 & 0,52 & 0,45 & 0,48 & 0,48 & 0,47 \\
\hline & $\mathrm{F}(\min )$ & 47,70 & 48,32 & 45,16 & 45,96 & 45,83 & 47,73 & 45,39 & 45,86 & 46,45 & 45,40 & 45,71 & 46,25 \\
\hline \multirow[t]{3}{*}{ Ciclo 02} & Temp $\left({ }^{\circ} \mathrm{C}\right)$ & $121,44 \pm$ & $121,45 \pm$ & $121,45 \pm$ & $121,37 \pm$ & $121,37 \pm$ & $121,55 \pm$ & $120,93 \pm$ & $120,91 \pm$ & $121,05 \pm$ & $121,00 \pm$ & $120,81 \pm$ & $121,00 \pm$ \\
\hline & média $\pm \mathrm{SD}$ & 0,47 & 0,45 & 0,44 & 0,48 & 0,50 & 0,53 & 0,47 & 0,49 & 0,46 & 0,49 & 0,47 & 0,47 \\
\hline & $\mathrm{F}(\mathrm{min})$ & 53,05 & 53,21 & 51,96 & 52,20 & 54,51 & 47,44 & 47,52 & 47,27 & 48,76 & 48,27 & 46,17 & 48,15 \\
\hline \multirow[t]{3}{*}{ Ciclo 03} & $\mathrm{Temp}\left({ }^{\circ} \mathrm{C}\right)$ & $121,36 \pm$ & $121,46 \pm$ & $121,49 \pm$ & $121,45 \pm$ & $121,50 \pm$ & $121,10 \pm$ & $121,53 \pm$ & $121,22 \pm$ & $121,44 \pm$ & $121,31 \pm$ & $121,93 \pm$ & $121,10 \pm$ \\
\hline & média $\pm \mathrm{SD}$ & 0,51 & 0,55 & 0,53 & 0,49 & 0,54 & 0,58 & 0,51 & 0,53 & 0,48 & 0,49 & 0,45 & 0,44 \\
\hline & $\mathrm{F}(\min )$ & 50,55 & 51,63 & 52,27 & 51,56 & 52,35 & 57,46 & 47,79 & 52,63 & 49,23 & 51,48 & 50,02 & 57,95 \\
\hline
\end{tabular}

$\mathrm{F}_{121^{\circ} \mathrm{C}}{ }^{10^{\circ} \mathrm{C}}$ foi 64,86 minutos (ponto 05). Com este valor de $\mathrm{F}_{121^{\circ} \mathrm{C}}^{10^{\circ} \mathrm{C}}$, se simulássemos a redução logarítmica de esporos de Indicador Biológico (valor de $\mathrm{D}_{121^{\circ} \mathrm{C}}=3,68 \pm$ 0,43 minutos), teríamos: número de reduções logarítmicas (n) $=\mathrm{F}_{121^{\circ} \mathrm{C}} 0^{\circ} \mathrm{C} / \mathrm{D}_{121^{\circ} \mathrm{C}}, \mathrm{n}=64,86 / 3,68 \ldots \mathrm{n}=17,6$ reduções logarítmicas.

Portanto, mesmo nestas condições teríamos S.A.L. mínimo de $10^{-12}$ para os esporos de Indicador Biológico com população de $1,00 \times 10^{6} \mathrm{UFC} /$ fita e valor $\mathrm{D}_{121^{\circ} \mathrm{C}} \mathrm{de}$ $3,68 \pm 0,43$ minutos. Este nível de segurança de esterilidade é bem maior que o sugerido pela Farmacopéia Americana (1990), para alimentos, que é de $10^{-6}$.

Conforme indicado na Figura 5, no tempo de $53 \mathrm{mi}-$ nutos, o valor $\mathrm{F}_{121^{\circ} \mathrm{C}}{ }^{10^{\circ} \mathrm{C}}$ foi de 44,00 minutos e $\mathrm{n}=12$ (reduções logarítmicas). Nestas condições já teríamos S.A..L mínimo de $10^{-6}$ para os esporos de Indicador Biológico com população de $1,00 \times 10^{6} \mathrm{UFC} /$ fita e valor $\mathrm{D}_{121^{\circ} \mathrm{C}}$ de $3,68 \pm$ 0,43 minutos. Portanto, o processo apresenta segurança além do necessário, para esterilização do produto protéico vegetal, mesmo para a condição mais crítica.

A Tabela III apresenta os resultados de análises realizadas em amostras do produto colhidas após a fase de mistura final de todos os ingredientes (figura 2). A contagem de mesófilos aeróbios e anaeróbios variou de 4,3-7,5 $\log$. Constatou-se aumento de $1 \log$ na contagem de termófilos aeróbicos e de $2 \log$ na de termófilos anaeróbicos, em relação à fase anterior do processo. Os demais resultados estão próximos aos obtidos na proteína de soja moída, o que indica que os outros ingredientes (sal, cebola, alho, gordura vegetal e condimentos) não altera-

TABELA II - Valores de temperatura média $\left({ }^{\circ} \mathrm{C}\right)$ e de $\mathrm{F}_{121^{\circ} \mathrm{C}}{ }^{10^{\circ} \mathrm{C}}$ em minutos, em cada ponto para cada ciclo de penetração de calor

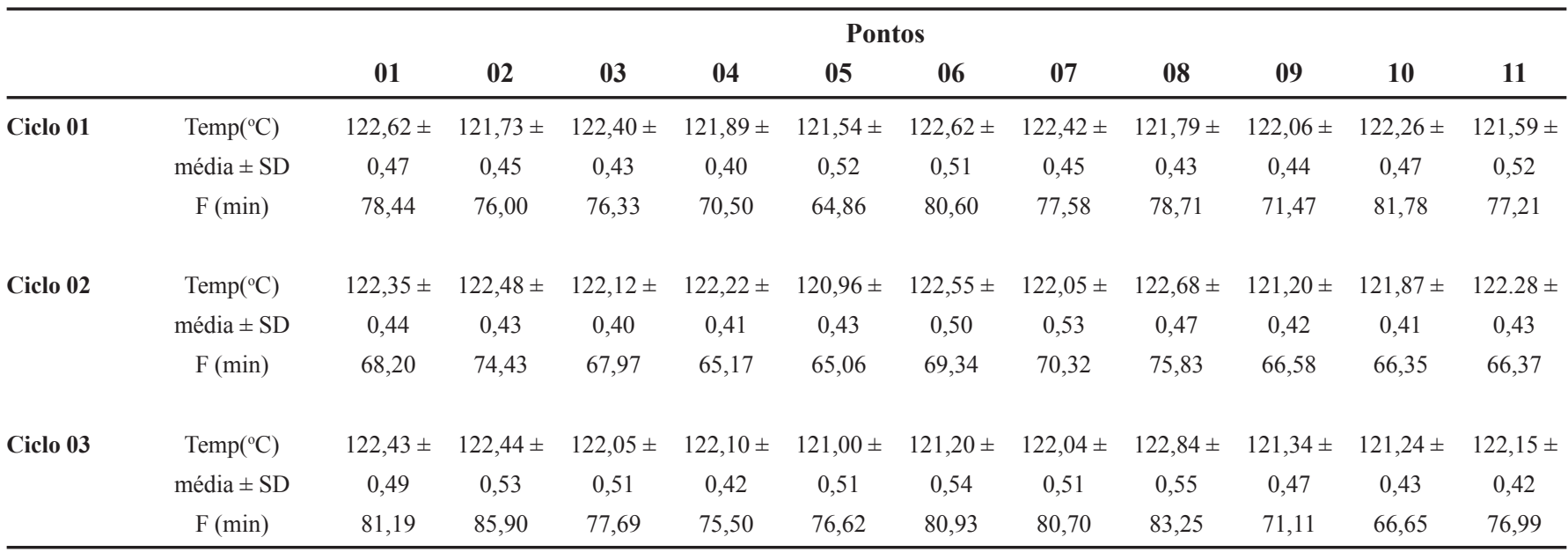




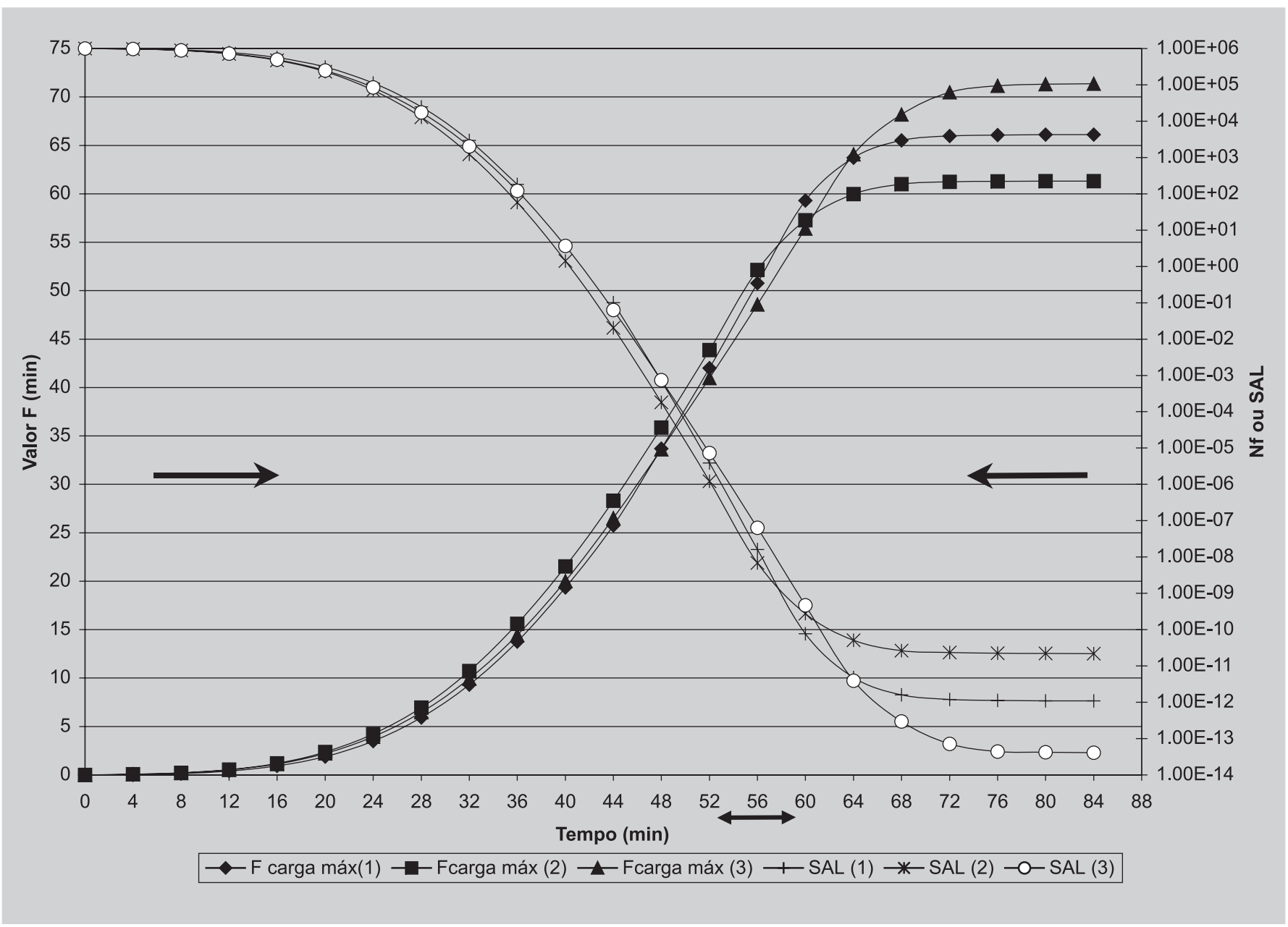

FIGURA 5 - Valor F e S.A.L. - Três estudos de penetração de calor (latas de 850 g).

TABELA III - Após mistura final dos ingredientes - Pré-esterilização

\section{Dados experimentais ( Log [UFC/g])}

\section{Amostras}

\section{Grupos de Microrganismos}

Contagem de mesófilos aeróbicos

Contagem de mesófilos anaeróbicos

Contagem de termófilos aeróbicos

Contagem de termófilos anaeróbicos

Bolores e leveduras

Coliformes

Coliformes fecais

Esporos de mesófilos aeróbicos

Esporos de mesófilos anaeróbicos

Esporos de termófilos aeróbicos

Esporos de termófilos anaeróbicos

\begin{tabular}{|c|c|c|c|c|c|c|c|c|c|c|c|}
\hline 1 & 2 & 3 & 4 & 5 & 6 & 7 & 8 & 9 & 10 & Mínimo & Máximo \\
\hline 7,54 & 6,39 & 6,39 & 6,50 & 6,34 & 7,30 & 6,38 & 6,54 & 6,20 & 6,40 & 6,20 & 7,54 \\
\hline 6,80 & 6,39 & 4,39 & 6,47 & 4,54 & 6,39 & 5,50 & 5,39 & 6,30 & 4,39 & 4,39 & 6,80 \\
\hline 3,20 & 1,00 & 3,00 & 1,00 & 0,00 & 3,17 & 1,00 & 1,00 & 0,00 & 2,39 & 0,00 & 3,20 \\
\hline 3,39 & 1,00 & 1,00 & 3,17 & 1,00 & 3,30 & 1,00 & 1,00 & 1,00 & 1,00 & 1,00 & 3,39 \\
\hline 2,69 & 3,34 & 3,55 & 3,39 & 3,38 & 3,87 & 3,50 & 3,39 & 3,39 & 3,70 & 2,69 & 3,87 \\
\hline 3,38 & 3,38 & 3,38 & 3,38 & 3,38 & 3,38 & 3,38 & 3,38 & 3,38 & 3,38 & 3,38 & 3,38 \\
\hline 3,38 & 3,38 & 3,38 & 3,38 & 3,38 & 3,38 & 3,38 & 3,38 & 3,38 & 3,38 & 3,38 & 3,38 \\
\hline 3,54 & 4,39 & 3,39 & 3,39 & 3,39 & 3,47 & 4,39 & 3,17 & 3,38 & 3,34 & 3,17 & 4,39 \\
\hline 3,39 & 4,45 & 4,34 & 4,20 & 3,59 & 4,39 & 3,87 & 3,34 & 4,38 & 3,39 & 3,39 & 4,45 \\
\hline 1,00 & 1,00 & 1,00 & 0,00 & 0,00 & 1,00 & 1,00 & 0,00 & 1,00 & 0,00 & 0,00 & 1,00 \\
\hline 1,00 & 1,00 & 1,00 & 1,00 & 0,00 & 1,00 & 0,00 & 1,00 & 1,00 & 1,00 & 0,00 & 1,00 \\
\hline
\end{tabular}

Intervalo 
ram significativamente a biocarga do produto na fase de mistura pré-esterilização. A proliferação das populações microbianas presentes na matéria-prima proteína de soja moída apresentaram risco potencial ao processo, constituindo-se em ponto crítico de controle.

\section{CONCLUSÕES}

A validação física do autoclave confirmou distribuição homogênea do calor nos 12 pontos distribuídos na câmara vazia e repetibilidade dos ciclos.

As validações física e biológica da esterilização do produto protéico vegetal confirmaram distribuição homogênea do calor no produto, sem destacar pontos mais frios ou mais quentes. Para os ciclos de autoclavação realizados com carga máxima do produto, o menor valor $\mathrm{F}_{121^{\circ} \mathrm{C}}{ }^{10^{\circ} \mathrm{C}}(64,86$ minutos $)$ garantiu nível de esterilidade (S.A.L.) de pelo menos $10^{-12}$ em relação ao indicador biológico de B. stearothermophilus ATCC 7953 (valor $\mathrm{D}_{121^{\circ} \mathrm{C}}$ de 3,68 $\pm 0,43$ minutos e população média de $1,00 \times 10^{6}$ esporos por fita). Para todas as operações de esterilização a presença de esporos sobreviventes no indicador biológico não foi detectada.

\section{ABSTRACT}

\section{Thermal processing validation of a canned vegetal protein product}

Process validation in the Food and Pharmaceutics Industries is one of the most important tools meant to guarantee quality, making safe and trustworthy products. Physical and biological validations were performed in the terminal sterilization of a canned vegetal protein product. Physical validation of the autoclave has been proceeded in three empty chamber cycles and 12 temperature sensors. It has been confirmed to the geometrically distributed spots inside the autoclave that the maximum temperature difference between one and another spot has been $1.0^{\circ} \mathrm{C}$ concerning the average chamber temperature $\left(122^{\circ} \mathrm{C}\right)$. Sterility Assurance Level (S.A.L.) of at least 10 $0^{-12}$, in relation to biological indicator of $\mathrm{B}$. stearothermophilus with $\mathrm{D}_{121^{\circ} \mathrm{C}}$ value of 3.68 minutes and average spore population of 1,00 $\times 10^{6}$ per strip, was obtained. Despite the absence of a margin of safety for canned products sterilization, periodical validation of an autoclave has provided greater trust on the sterility evaluation than the simple incubation test of some samples, recommended by the Brazilian Ministry of Health.
Autoclave. Sterilization. Canned food.

\section{AGRADECIMENTOS}

FAPESP, CNPq e Produtos Alimentícios Superbom.

\section{REFERÊNCIAS BIBLIOGRÁFICAS}

APHA. AMERICAN PUBLIC HEALTH ASSOCIATION. Compendium of methods for the microbiological examination of foods. $13 \mathrm{ed}$. Washington: APHA, 1992. $157 \mathrm{p}$.

BRASIL. Ministério da Saúde. Agência Nacional de Vigilância Sanitária-ANVISA- Portaria n ${ }^{\circ} 500$ de 13 de outubro de 1997 - Anexo I - Validação do Processo de Esterilização por Vapor. Disponível em: <http:// www.anvisa.gov.br>. Acesso em: 24 jun. 2002.

BRASIL. Ministério da Saúde. Agência Nacional de Vigilância Sanitária-ANVISA-Resolução-RDC n ${ }^{\circ} 12$, de 2 de janeiro de 2001 - Regulamento Técnico sobre Padrões Microbiológicos para Alimentos. Disponível em: $<$ http://www.anvisa.gov.br $>$. Acesso em: 25 jun. 2002.

FARMACOPÉIA brasileira. 4. ed. São Paulo: Atheneu, 1988. pt. 1 , cap. X. $1-2$.

GERMER, S.P.M. Avaliação dos desvios no processamento térmico de alimentos em conserva. Informativo FRUTHOTEC, São Paulo, v.3, n.2, p. 2-3, 1997.

INTERNATIONAL FEDERATION OF THE PHARMACEUTICAL INDUSTRIES. Sterility assurance based on validation of the sterilization process steam under pressure. J. Parenter. Sci. Technol., Philadelphia, v. 43, n. 5, p. 226-230, 1989.

INTERNATIONAL FEDERATION OF THE PHARMACEUTICAL INDUSTRIES. Validation and control of non-standard sterilization process. J. Parenter. Sci. Technol., Philadelphia, v. 47, n. 1, p. 1-15, 1993.

ISO. INTERNATIONAL ORGANIZATION FOR STANDARDZATION. Sterilization of health care products - Requirements for validation and routine control - Industrial moist heat sterilization. 1994. [ISO 11134] 
ISHISAKI, E. T. Validação da autoclave na esterilização de solução parenteral. São Paulo, 1998. 129p. [Dissertação de Mestrado - Faculdade de Ciências Farmacêuticas da Universidade de São Paulo. Departamento de Tecnologia Bioquímico-Farmacêutica].

MARTÍNEZ, A.; OCIO, M.J.; RODRIGO, F.; Heat resistance of Bacillus stearothermophilus spores in alginate-mushroom puree mixture. Int. J. Food Microbiol., n. 29, p. 391-395, 1996.

PDA. PARENTERAL DRUG ASSOCIATION. Technical Report N. 33: Evaluation, Validation and Implementation of New Microbiological Testing Methods. J. Pharm. Sci.Technol., Tokyo, v. 54, n. 3 suppl.TR33, p. 15-42, 2000.

USP. UNITED States Pharmacopeia. 22 ed. Rockville: United States Pharmacopeial Convention, 1990. p.17061710, 1625-1626.
VESSONI PENNA, T. C. Validação de processos de esterilização I. Conceitos básicos Laes \& Haes, São Paulo, v. 15, n. 88, p. 46-48, 1994.

VESSONI PENNA, T. C.; MACHOSHVILI, I. A. Esterilização térmica. Conceitos básicos da cinética de morte microbiana. Rev. Farm. Bioquím. Univ. São Paulo, v.34, supl.1, p.1-5, 1997.

VESSONI PENNA, T. C.; MACHOSHVILI, I. A.; BASTON, L.M. Importância da autoclave em lactário hospitalar. Laes \& Haes, São Paulo,v. 16, n. 91, p. 68-74, 1994.

Recebido para publicação em 11 de junho de 2002. 